\title{
Eduardo Chillida, a la escucha del latir de las cosas
}

\section{Eduardo Chillida. Listening to the heartbeats of the world}

\author{
María Antonia DE CASTRO \\ mariaadecastro@gmail.com
}

\section{Resumen}

Eduardo Chillida, a la escucha del latir de las cosas, es algo más que una imagen metafórica sobre la obra de este escultor, es un abordaje al modo en que este artista se relaciona con el mundo. A partir del convencimiento de que existe una posibilidad de conexión entre la naturaleza de los materiales y su propia naturaleza, el artista se exige un estado contemplativo que afecta a todo el proceso creador, desde la elección de esos materiales a la conformación final de la obra. Tal actitud vital, intelectual y espiritual, para la que el arte es la prolongación de un comportamiento ante el mundo y de una manera de entender éste, resulta determinante en la razón de ser de las formas abstractas, y el punto común de partida que identifica a todos los grandes artistas abstractos de la generación de Chillida. Entendiendo este modo de enfrentar la creación como uno de los rasgos más definitorios de la actividad escultórica de Eduardo Chillida, el artículo también se refiere al sentido que informa a la abstracción, no importa de qué tiempo y lugar, a lo largo de la historia.

Palabras clave: formas abstractas, materiales, escucha, integración, mundo

\begin{abstract}
Eduardo Chillida, listening to the beat of things, is something more than a metaphoric image of the work of this sculptor, it is an approach to the way in which this artist relates to the world. On the basis on his certainty that there is a possibility of connection between the nature of the materials and his own
\end{abstract}


nature, the artist demanded himself a contemplative state that affects all the creative process, from the election of the materials to the final shape of the work. Such a vital, intellectual and spiritual attitude to which art is the continuation of a behaviour towards the world and of a way of understanding it, becomes determinant in the rationale of the abstract forms and the common starting point that identifies all the great abstract artists of Chillida's generation. Understanding this way of facing the creation as one of the most defining features of the creative activity of Eduardo Chillida, the article also reviews the meaning that informs abstraction, no matter in which time and place, throughout the history of forms

Key words: abstract forms, materials, listening, integration, world

Chillida pertenece a la generación de artistas que en los años centrales del siglo XX abraza la abstracción y la empuja hacia los límites de sus posibilidades. La decidida adopción del lenguaje abstracto, que había sido ya iniciada por los artistas de las vanguardias, era algo que ocurría por primera vez en la historia de la modernidad de Occidente. Los anteriores ejercicios abstractos conocidos pertenecen, en esta parte del mundo, a periodos previos a la modernidad -si por tal se entiende la preeminencia otorgada a la razón como medio de conocimiento-e, incluso, a etapas anteriores a la historia. A Chillida le tocaría cumplir esa misión en el terreno del volumen, o mejor, de la tercera dimensión.

Las formas abstractas no constituyen una simple alternativa que afecte al exclusivo terreno de la plástica, sino que se trata de una elección vinculada a toda una serie de premisas y condiciones, también de orden abstracto, que conciernen a todo el proceso de creación, a la propia idea de lo que es el arte, a la función del artista y, también, a otros órdenes extra-estéticos de carácter más amplio.

La elección de la abstracción para los artistas de esta generación, que despunta creativamente en la mitad del siglo XX, conlleva pues una toma de postura espiritual, una reflexión intelectual y una actitud ética, que se vinculan, irremediablemente, con una determinada visión del mundo y del ser humano en el mundo. De manera que, no ha de resultar extraño que, en el corpus de escritos y palabras con el que estos artistas se expresan y también en la bibliografía que interpreta su obra, aparezcan palabras y conceptos vinculados con la idea central que tienen del arte como un medio de conocimiento de lo que está más allá de la apariencia visual de la naturaleza.

Nuevos términos como, entre otros, la visión, lo desconocido, el misterio, la necesidad, la revelación, la experiencia, el acontecimiento, lo numinoso, la verdad, el 
ritual, la esencia, la experimentación, el compromiso, empiezan a integrarse en los discursos que interpretan las formas abstractas en detrimento de otros que se impugnan tales como: estilo, técnica, academia, método, norma, canon, modelo, ley... Con las formas abstractas se introduce en el arte una constelación de nociones que proceden del ámbito espiritual e, incluso, del área de las religiones o, lo que resulta más excéntrico, de esferas también contestadas por la razón, como la alquimia.

Nicolas Bourriaud en su libro Formas de vida. El arte moderno y la invención de sí, afirma que "El arte moderno nace en el momento en que el artista se acerca al imaginario ascético del alquimista, investigador solitario y gran intelectual. [...] los métodos obsesivos y el espíritu experimental de los pintores de vanguardia se confunden con la disciplina de la alquimia, de la que heredan léxico y objetivos simbólicos: hacer brotar el espíritu enterrado en la materia". ${ }^{2}$ Esta apreciación ya había sido observada por Anièla Jaffé, destacada miembro de la escuela de Jung, quien anotaba que el empeño de los artistas modernos por ahondar en la esencia de la materia era similar a la búsqueda en tiempos pasados del espíritu terrestre al que los alquimistas llamaban Mercurius."El espíritu mercurial es el símbolo de ese espíritu que los artistas presentaban o buscaban detrás de la naturaleza de las cosas, detrás de la apariencia de la naturaleza"2. Jung asimilaba esta actividad desarrollada en el ámbito de lo material con un movimiento de introspección hacia el fondo de la conciencia. ${ }^{3}$

Si traigo esto a colación es para dar una idea del género de implicaciones que los artistas estaban activando en su despojar a la forma y al material de otros referentes que no fueran ellos mismos, en su deseado afán por llegar al sentido último de ambos, a través de un lenguaje que no podía ser otro que el abstracto.

De manera que las formas abstractas llegan integradas en un sistema complejo de ideas que trascienden la problemática plástica tal y como venía siendo entendida en Occidente desde el Renacimiento -aunque el problema de las formas esté siempre en el punto de partida-. Ese sistema de pensamiento es el que, a su vez, vincula entre sí a todas las formas de la abstracción que, en la historia o antes de la historia, se han dado y, lo más sorprendente, que son comunes a todas las culturas, no importa de qué lugar geográfico ${ }^{4}$. No es

\footnotetext{
${ }^{1}$ Bourriaud, N., Formas de vida. El arte moderno y la invención de sí, Murcia, CENDEAC, 2009 , p. 35

${ }^{2}$ Jaffé, A., «Le Symbolisme dans les Arts Plastiques» en Jung, C.G. (dir.), L'Homme et ses Symboles, Paris, Robert Laffont, 1964, p. 262

${ }^{3}$ Ibidem, pp. 264-265

${ }^{4}$ Un desarrollo ilustrado de las diferencias (religiosas, sociales, económicas, políticas etc.) entre los ámbitos en los que se desarrollan las formas figurativo/ naturalistas y las formas abstractas a lo largo de ciertos hitos de la historia del arte en de Castro, M. A., Función y Forma, Madrid, CIDAF, 2003, (conferencia).
} 
momento de detenerse aquí sobre este hecho clave, sólo apuntar que un esquema básico de las secuencias de nociones que acompañan a las dos modalidades formales básicas: la figuración naturalista y la abstracción, había sido el tema brillantemente esbozado por el esteta Wilhelm Wörringer en su tesis doctoral publicada en la Viena de principios del pasado siglo Abstraktion und Einfühlung, editada en español con el título de Abstracción y Naturaleza .

Estas premisas hacen muy particularmente interesante el estudio de las formas abstractas que retoma la modernidad desde las vanguardias, después de siglos de arrumbamiento a la sombra de la opción figurativa-naturalista que en Occidente, y procedente de la Grecia clásica, había alcanzado brillantes y variados desarrollos durante veinticinco siglos, interrumpidos por las no desdeñables diez centurias en las que se desarrollan las artes de la Alta y Baja Edad Media y la fugaz alternativa que supusieron las formas geométricas islámicas en el extremo sur de la Península Ibérica.

En un mundo que caminaba decidido hacia el positivismo materialista, la abstracción y su linaje de signos y contenidos también abstractos y espirituales introduce el que fue un intento de pensar y crear el arte desde un nuevo concepto de humanismo.

Humanismo y espiritualidad que traían un nuevo signo, el de ser más terrenales que trascendentales, pues, como intelectuales que fueron estos artistas su ámbito de conocimiento y curiosidad también se dirigió hacia ciencias como la física y sus audaces descubrimientos sobre la materia, y hacia la psicología que hizo otro tanto acerca de la interioridad de la psique humana.
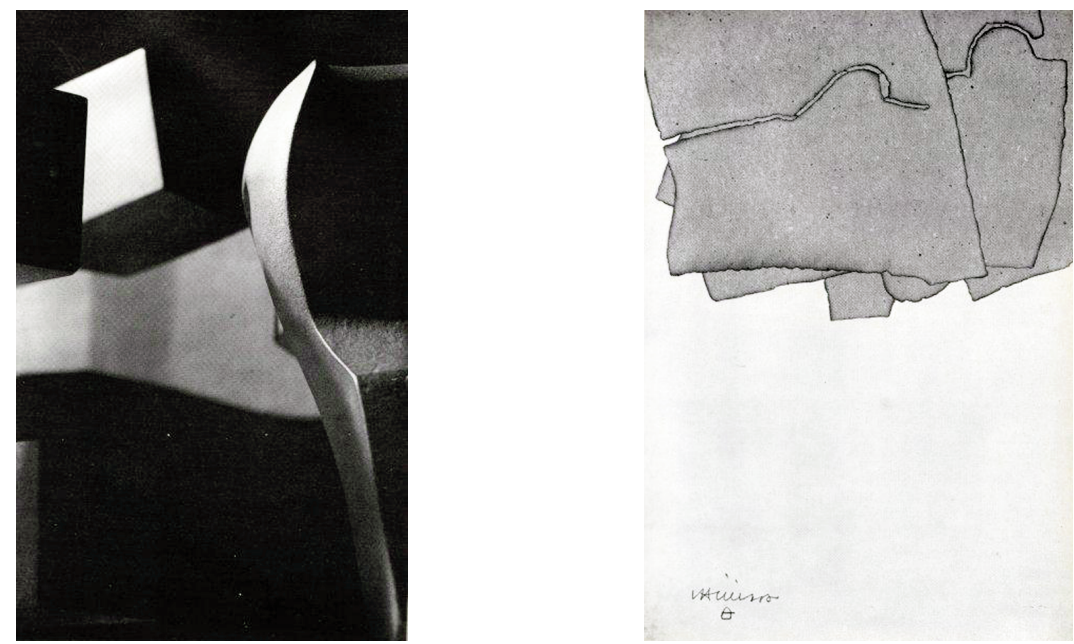
${ }^{5}$ Wörringer, W., Abstracción y Naturaleza, México, Fondo de Cultura Económica, 1966, (1
ed. 1907). 


\section{La abstracción en España}

España durante el periodo de creación, desarrollo y aceptación de la modernidad había sido un territorio marginal. Y no porque no hubiera artistas que dieran con las claves de la gran revolución moderna de las formas, sino porque no encontraron en el propio país ni respuesta, ni abono con el que alimentar sus búsquedas. Todos los creadores españoles que integraron las vanguardias y crearon el arte moderno, un arte que se expresaba en el lenguaje abstracto, lo hicieron desde su exilio -más o menos prolongado- en París.

Hubo sólo una excepción a esta regla y vino dada por el surrealismo. No todos los artistas surrealistas practicaron el lenguaje abstracto pero, sin embargo, sí lo consideraron como corriente del pensamiento, como actitud vital y como llamada de atención hacia otras formas del arte ciertamente abstractas -las culturas llamadas primitivas-y hacia otros géneros de espiritualidad. Y, también, como movimiento inspirador de ciertos métodos o procesos de creación -que incluían la incorporación del azar y el rechazo al racionalismo-, el Surrealismo va a ser determinante en la aparición de las grandes obras abstractas que empiezan a realizar en España, en el lustro que va de 1950 a 1955, los artistas de la generación de Eduardo Chillida. Un periodo breve para que se produjera una eclosión creativa tan espectacular en el terreno de la abstracción.

Fue en esos años cuando, por primera vez en España, el lenguaje abstracto canalizaba la expresión del arte, desde aquellos remotos periodos de la historia del arte, entonces recuperados, como la Edad Media, o la prehistoria peninsular, o el periodo arcaico del arte griego, que Chillida vió en el Louvre, muy poco antes de dar con su propio lenguaje formal.

En España una generación de artistas, entre los que estaba Chillida, tomaba, mediado el siglo XX, el camino decidido de la abstracción pasados unos primeros balbuceos pseudo-figurativos. En su caso tal proceso se materializó en los numerosos dibujos inmediatos a 1950. En ese tránsito, de la figuración esquemática al lenguaje abstracto, hubo momentos decisivos y es necesario recordar que, para Palazuelo, Tàpies, Millares y Chillida la estancia en París volvió a ser tan determinante como lo había sido para la generación vanguardista. Sólo que ellos volvieron a su tierra de nacimiento, donde dieron definitivamente con las claves de su lenguaje artístico - exceptuando a Palazuelo que se quedó en París veinte años, desde 1948 hasta 1968-.

Para Chillida los dos años que pasó allí, entre 1949 y 1951, compartiendo estudio precisamente con Pablo Palazuelo, formado en la arquitectura como él, marcaron su vocación decidida hacia las formas abstractas. 


\section{Las formas abstractas, problemas y preguntas}

Las formas abstractas plantean desde el inicio del trabajo del artista un problema, su aleatoriedad. Hay que pensar que el artista que decide adentrarse en el territorio de la abstracción, al contrario del artista no abstracto, no atiende a las referencias que le ofrece la realidad visual. Su campo de actuación está completamente abierto, no tiene condiciones, ni límites, en un principio, al menos. A partir de esa vertiginosa apertura, su preocupación va a centrarse en encontrar las condiciones que confieran el sentido de lo verdadero y de lo necesario a sus formas abstractas, de manera que el indeseado fantasma de lo caprichoso y aleatorio sea exorcizado. Pero ¿de qué modo puede el artista con voluntad de abstracción ceñir sus formas a un parámetro tan resbaladizo como es lo verdadero? De esa cuestión surge otra inmediata: ¿qué quiere decir el concepto de verdad referido a la obra?
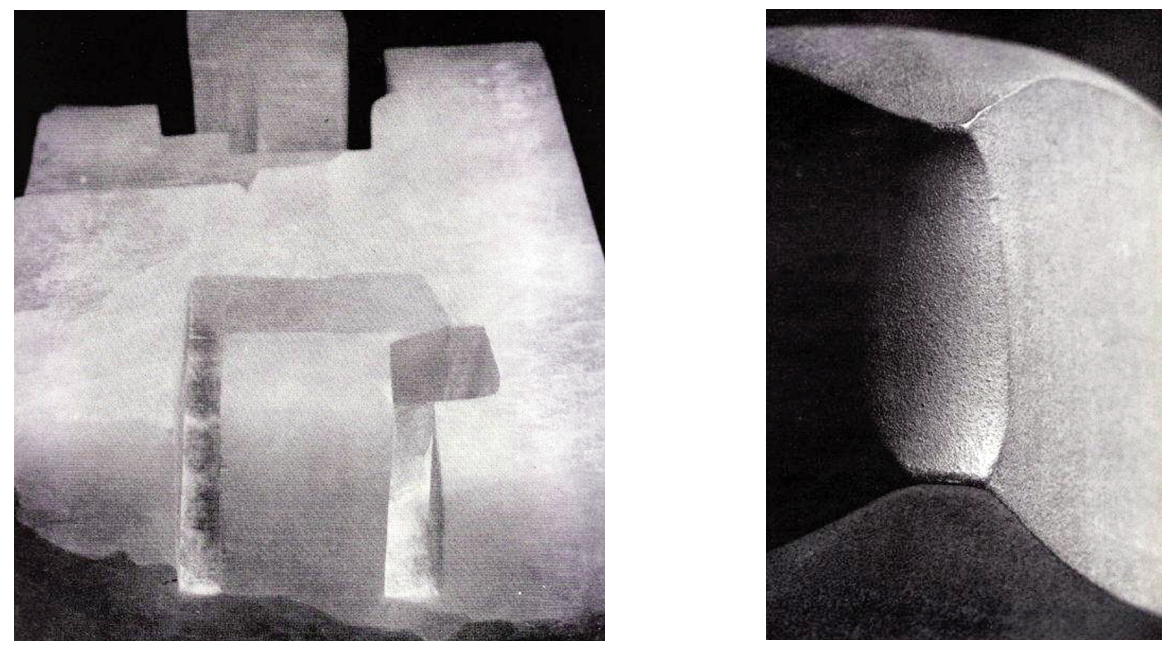

La respuesta hay que buscarla en la propia obra, puesto que no existe ya la referencia exterior, y encaminarla por vía de lo que la obra es en sí misma. "Si la obra no se explica desde sí misma, vanos son todos los razonamientos circunstanciales" dice Eduardo Chillida a Santiago Amón en una entrevista con título bien significativo: Materia, experiencia y acontecimiento natural. ${ }^{6} \mathrm{Si}$ la obra ha de explicarse en razón de si misma, sin contar con el recurso de ninguna exterioridad ¿qué cualidades de sí misma puede y debe conquistar?

${ }^{6}$ Amón, S., "Materia, experiencia y acontecimiento natural", Revista de Occidente, n 3 , (1976), Madrid, p. 45. 
Busquemos la respuesta en lo que es la obra de formas abstractas, por oposición a lo que es en sí misma la obra de formas figurativo-representativas. Esta última es una re-presentación que tiene como referencia la apariencia visual de las formas visibles, eso a lo que llamamos genéricamente "realidad". Asumido lo cual, la obra de formas abstractas, que tiene como referencia y explicación a sí misma, habrá de asumir su categoría de presencia. Lo cual requiere poseer una entidad poderosa para poderse erigir como presencia en sí, como totalidad de sentido sin más referencias con la visualidad exterior. Y ¿qué cualidad hay de más constatable en lo que reconocemos como una presencia, que la fuerza emanada por su propia vitalidad?

Heidegger, que fue tan decisivo en la vida y en la obra de Chillida, responde a la cuestión que él mismo plantea sobre la cualidad o cualidades que debe poseer una obra: “¿Qué instala la obra en tanto que obra? Alzándose en sí misma, la obra abre un mundo y lo mantiene en una reinante presencia."”

La obra, para ser presencia, ha de abrir un mundo, ser mundo en primera instancia y, además, -según Heidegger- ha de mantener ese mundo reinante. Dos actividades que implican la necesidad de poseer una vida propia, una razón de ser inherente, un latir y una existencia en permanencia, una latencia en el tiempo. El latir, esa cualidad de vida propia, es, para los artistas que habían elegido las formas abstractas, aquello que otorga verdad y autenticidad a la obra, erigiéndose como contraposición a la verosimilitud con respecto a las cosas del mundo -en sus circunstancias concretas- que es en lo que reside la verdad de las formas figurativo-naturalistas.

Hagámonos una pregunta más ¿a qué existencia en permanencia y a qué latir ha de aspirar la obra de formas abstractas? Para hallar la respuesta utilicemos el mismo camino anterior en sentido inverso y volvamos a la obra de arte de formas naturalistas que, como re-presentación que era, tenía como referencia las formas singulares de las cosas en su circunstancia concreta. Luego, entonces, la obra de arte de formas abstractas tendrá como eje de referencia lo general, universal e intemporal; y lo general e intemporal de las cosas del mundo reside en lo que los artistas vanguardistas llamaban su "esencia", entendida como aquello que trasciende lo individual y aleatorio de la circunstancia.

La puesta en escena de la esencia es, pues, aquello que otorga verdad y llena de vida a la obra abstracta, como contraposición a la verosimilitud, en la que reside la verdad de las formas figurativas. En este aspecto Chillida se aviene a la idea que enuncia Heidegger sobre la función que debe cumplir la obra de arte cuando escribe: "Así pues, en la obra no se trata de la reproducción del

${ }^{7}$ Heidegger, M., Caminos de bosque, Madrid, Alianza, 1996, p. 36. 
ente singular que se encuentra presente en cada momento, sino más bien de la reproducción de la esencia general de las cosas"».

Es, pues, en la búsqueda de la esencia de las formas y de los materiales, como un escultor abstracto, como Chillida, va a encontrar el camino que le salve del problema de la aleatoriedad de las formas abstractas. Brancusi, que se cuenta, junto con Picasso, entre los dos artistas a los que Chillida nombra como sus dos maestros ${ }^{9}$, había asentado la base de la creación abstracta sintetizando y abstrayendo de las formas orgánicas lo esencial.

\section{A la escucha del latir de las cosas}

Pero si para Brancusi la esencia de una escultura debía ser extraída básicamente a partir de la abstracción de las formas orgánicas de la cosa tomada como referencia, para Chillida, como para el resto de los artistas de su generación, lo esencial está un paso más allá, no en la cosa, sino en los propios medios del artista: los materiales, los ritmos, los vacíos...

Pero ¿A qué materia nos referimos cuando hablamos de la obra de Eduardo Chillida?

Chillida abandona pronto la piedra para huir de su entidad de masa cerrada. "La escultura de la piedra encierra, para Chillida un espacio denso, un espacio que el creador humano ha dejado sin trabajar. Para ayudarnos a gozar de un espacio material reanimando las fuerzas esenciales, la piedra no puede dar más." nos dice Gaston Bachelard ${ }^{10}$.

Por ese motivo a Chillida le interesa, sobre todo, el espacio, como alternativa y contrario que vitaliza la densidad opaca de la materia piedra. De manera que la esencia de su escultura va a estar tanto dentro como fuera del o entre el material. Por eso se dirige hacia el hierro, -como también lo había hecho Picasso tras tratar la piedra-. En muchas de sus obras más características, como el Peine del viento, la escultura se constituye a partir de vigas de hierro que se integran en su otro material, el espacio. Y es curioso observar que esas vigas de hierro podían verse como varillas agigantadas, el mismo tipo de elementos que había empleado Picasso para construir una de sus esculturas emblemáticas La mujer en el jardín, con la que, de paso, revolucionaría la escultura moderna e inspiraría la revolucionaria obra escultórica de Julio González, su maestro en el arte de la soldadura.

\footnotetext{
${ }^{8}$ Heidegger 1996, op.cit. (nota 7), p. 30

${ }^{9}$ Amón (1976), op.cit. (nota 6), p. 44

${ }^{10}$ Bachelard, G., en catálogo Chillida, Paris, Galerie Maeght, 1956
} 
Chillida encontraría la esencia de la escultura tanto dentro del material, como fuera, en la materia espacial que la circunda y que también la conforma internamente. De manera que para conseguir abrir un mundo y mantenerlo en la presencia reinante que es la manera en que Heidegger consideraba que una obra se hacía obra, Chillida se exige atender a las cualidades de todos los elementos que intervienen en ella: por un lado de los materiales, pero también, del espacio en el que va a intervenir como presencia. Y aquí es donde se introduce una de las actividades que el escultor Chillida se impone: la escucha del latir de las cosas. Escuchar el latir de la materia, pero también del lugar y del espacio en el que la escultura interviene, no como un monumento con su re-presentación cerrada y fija, sino como una presencia activa que abandona la fijeza y la naturaleza clausurada y cerrada sobre si misma de la escultura clásica, para devenir un acontecimiento.
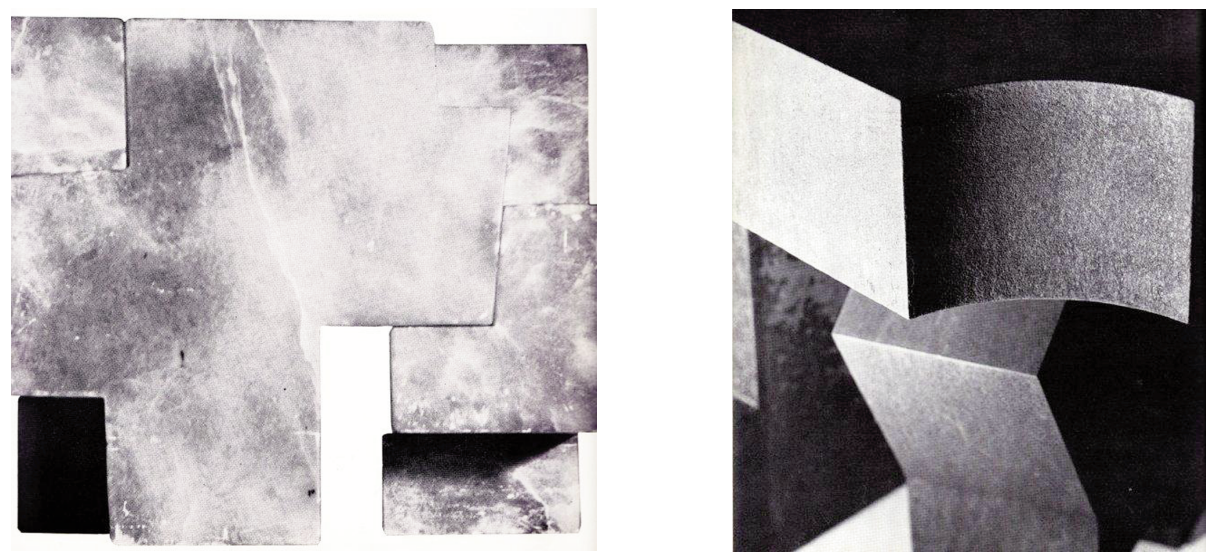

Hay, antes del contacto directo con el material y antes del proceso de conformación, un periodo previo a la realización de una escultura que es determinante en la vida futura de la obra: la elección del material apropiado. Chillida había dicho que "el material definitivo late en el pre-origen de la obra."11 Ya en esta fase a la que denomina pre-origen, el escultor alude a un latir del material, -lo que podría interpretarse en términos psicológicos como una acción de proyección de una vivencia interior del artista hacia el material que ha de ser el elegido-. Con ello el escultor da a entender que el material es concebido como algo que está dotado de una existencia propia, existencia que empieza a hacerse presente cuando es re-conocida como una vida a la que hay que atender porque es un elemento de la escultura tan decisivo como la forma. Es en ese

${ }^{11}$ Amón (1976), op.cit. (notas 6-8), p. 47. 
sentido en el que Chillida afirmaría que "La obra se plantea (y no a un nivel propiamente mental) en contacto inseparable con su materia definitiva" 12

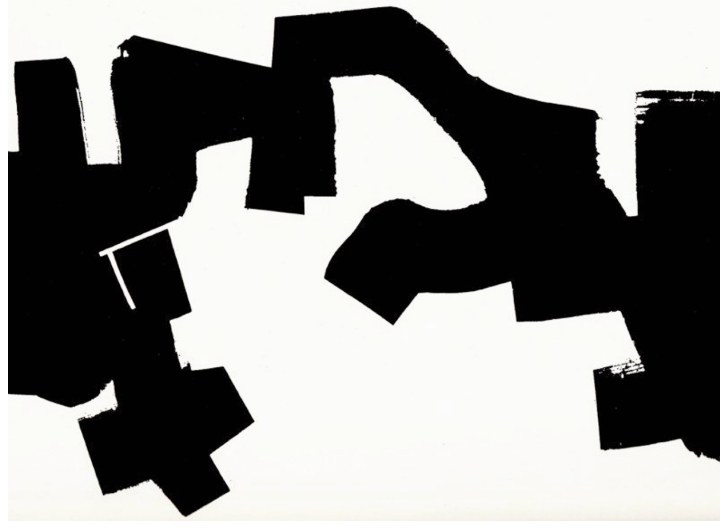

Chillida utilizaría la piedra, la madera, el hierro, el alabastro, el papel, la tierra chamota o el hormigón. Y respecto a esta variedad de materiales con sus cualidades específicas, el escultor distingue entre lo que se puede y lo que se debe hacer con los materiales, en virtud de lo que los materiales ofrecen de si mismos. Hacer filigranas sobre una piedra dura, por ejemplo, en un ejercicio de virtuosismo que contraviene la naturaleza del material, no le aporta a Chillida nada que le interese. Muy al contrario, para él será necesario en cualquier obra escuchar el latido de la materia, o, como afirma, "atender a la condición (al deber) que dicho material reclama desde sí." 13

Esto es a lo que Chillida se refiere cuando habla de lo que se debe hacer con el material: atender a "las leyes internas de la materia" a las que considera "las colaboradoras, fieles y exigentes, del escultor." ${ }^{14}$ Cada material tiene unas características físicas determinadas, una densidad y una resistencia, una temperatura de fundición, un índice determinado de refracción a la luz, en definitiva, una estructura interna. Se podría hablar pues de un espíritu que le es consustancial, y que por ello requiere de un instrumental y de un tratamiento adecuados a él. El trabajo del escultor, como el del alquimista, es el hacer brotar el espíritu enterrado en ella al conformarla como obra. La obra definitiva será una presencia vibrante si es resultado de la escucha de todas esas condiciones y posibilidades que moraban en el interior de la materia. "Mi trato con los materiales es de sumo respeto, aunque no de obediencia ciega. Cierto que

\footnotetext{
${ }^{12}$ Ibidem, p. 46.

${ }^{13}$ Ibidem, p. 46.

${ }^{14}$ Ibidem, p. 46.
} 
me impongo a ellos, pero escuchándoles, respetándoles. La experiencia me dice que hay muchas cosas que se pueden hacer con los materiales, pero que no se deben hacer"'15.

Con ello Chillida enuncia el que es tema de esta charla, la escucha de la materia para llegar a entender lo que es, el espíritu que lleva dentro y, actuando conforme a ello en el acto creativo, poder obtener una obra que sea verdad, presencia viva, porque responde a las cualidades de su esencia.

En este sentido, Octavio Paz escribía: "La escultura de Chillida nos impresiona, a primera vista, por su acentuada materialidad: más que formas en hierro o en granito, sus esculturas son el hierro mismo, el granito en persona. No son representaciones de ideas, sentimientos o sensaciones: son manifestaciones palpables de lo férreo y lo granítico." 16

Por otra parte, el sonido y la música en todas sus cadencias y tonos está presente en la vida cotidiana del escultor. En muchos de los títulos de sus obras se incluyen vocablos que proceden de lo sonoro, de lo que se escucha: Vibración, De música, Sonoridad, Pájaros, Vivaldi, Rumor de limites, Yunque de sueños, Viento, Resonancia, Silencios, Sonora, Música de las esferas, Lugar de silencio, Eco, Espacios sonoros, Canto rudo... También sabemos que Chillida escuchaba continuamente música, particularmente la música compuesta por Bach, que tanto le ayudó en los momentos difíciles que atravesó al final de su vida.
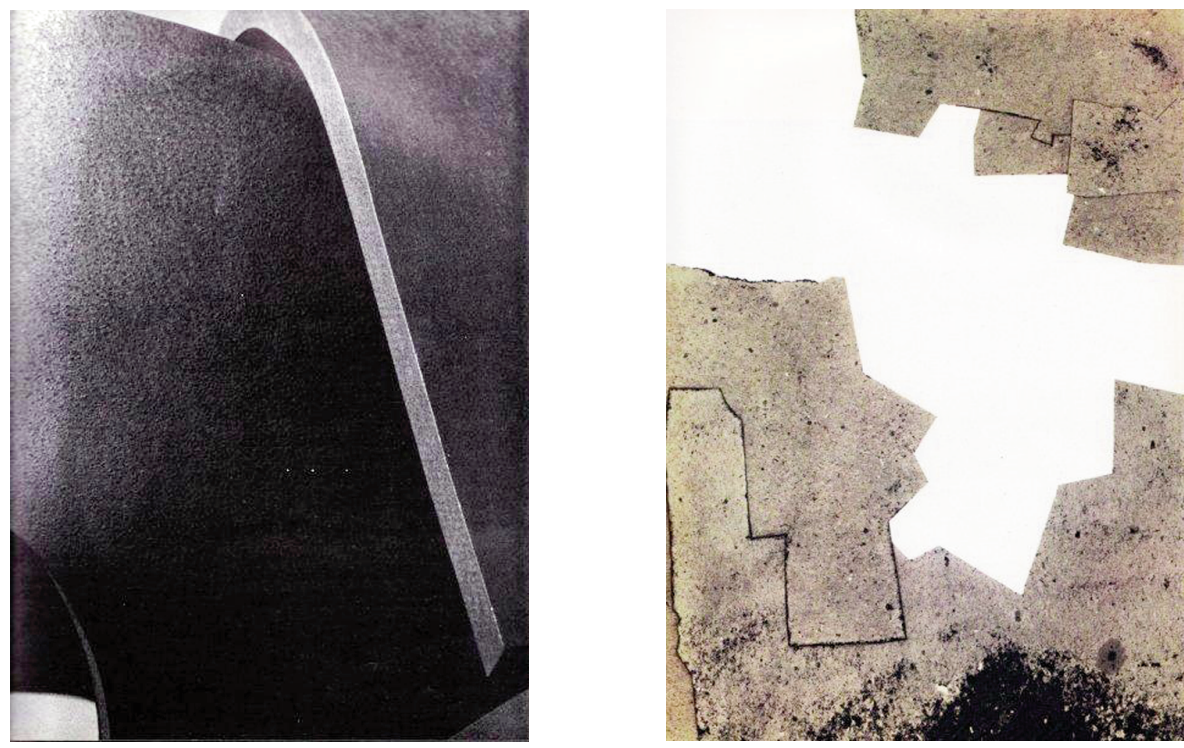

${ }^{15}$ Ibidem, p. 46

${ }^{16} \mathrm{Paz}, \mathrm{O}$. , "Chillida entre el hierro y la luz», en Catalogue. Chillida, París, Galerie Maeght, 1979 , p. 39. 


\section{Integración en el mundo}

En el título de la mencionada entrevista con Santiago Amón, aparecen dos conceptos más que, añadidos al concepto del material, forman la tríada nuclear de la creación abstracta de Chillida: la experiencia y el acontecimiento. Ambos son inherentes a la forma en que los artistas abstractos de esta generación entienden el arte.

Para ellos, y, por tanto, para Chillida, la obra ha de ser coherente con el material que la conforma, pero además debe de surgir de una experiencia original. Y esa experiencia se concentra en el proceso de creación mental y de conformación. Sobre el proceso mental de creación ya acabamos de hablar, ahora vamos a ver qué ocurre durante el proceso de conformación.

El proceso de conformación es para estos artistas de la generación abstracta un momento decisivo, y le conciben como un pasaje experimental azaroso en medio de lo desconocido, y ello, en la medida en que no hay un boceto previo, ni material ni mental, lo que aboca a que la forma definitiva dependa de ese proceso de conformación. Durante ese proceso y de alguna manera, a la materia le es permitido hablar por si misma para expresarse, mientras Chillida se impone a ella. Podría verse en esta actuación al unísono de materiales y artista una especie de entendimiento imprevisible o mágico entre el inconsciente y la conciencia, entre el azar y la voluntad.

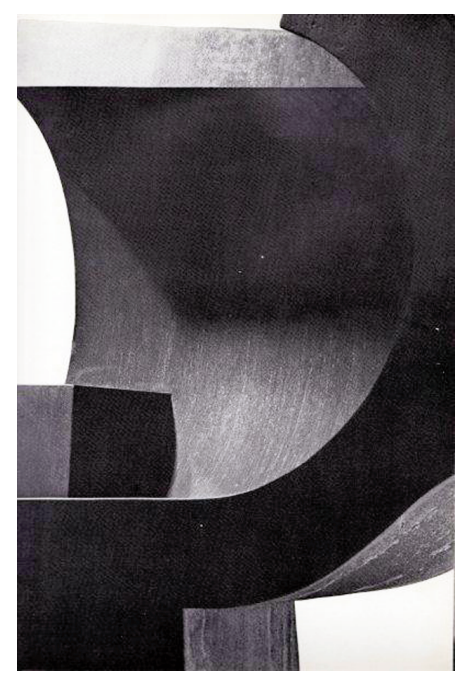

Eduardo Chillida nunca hizo fundidos sobre molde, esa predeterminación de la forma no le interesaba, porque eso descartaba la posibilidad de que el azar y las decisiones que se iban tomando en el proceso de transformación de 
los materiales en otras formas nuevas, formaran parte del acto creador. De manera que todos los artistas abstractos están imbuidos de una idea de arte según la cual a la forma final quedara incorporada una experiencia que por su originalidad, es decir, por todos los avatares específicos que coinciden en ella en el momento de hacerse, la convertía en experiencia única y necesaria. El tiempo de la creación de la obra se entiende, pues, como una experiencia en tiempo real cuyas circunstancias forman parte de la obra y dejan huellas en ella, de manera que, al integrarse a su conformación, le transfieren la cualidad de ser, ella también, un acontecimiento.

Hay algo de ritual en este proceso de conformación convertido en experimento, en la medida en la que "los rituales operan como reguladores de la experiencia, más allá de la conciencia reflexiva de los individuos" ${ }^{17}$. Un ritual en el que la voluntad de transformar la materia en forma, y la intuición sobre lo que el material "dice", como una entidad que tiene su propio espíritu, se confunden e integran.

El escuchar los materiales con la conciencia de que poseen su propio espíritu ofrece, sin duda, un componente animista; contando, además, con que también el espacio posee un espíritu, como un material más. El espíritu de los materiales, de las cosas y del mundo, no podría entenderse si no fuera porque un artista como Eduardo interioriza la idea de que el ser humano está integrado en el cosmos a través de su propia materia y de su propio espíritu. Y de que eso es lo que justifica la posibilidad de un poder oír y entender lo que, en el arte inmediato anterior, había sido sólo materia pasiva, mera exterioridad, objeto.

Ese re-ligamiento múltiple entre: formas y materiales e intencionalidad del creador, procede de la creencia en la continuidad del universo. Y su consecuencia es que, para Chillida, como para otros artistas que operaban con las formas abstractas, su actividad artística fuera inseparable de su comportamiento en la vida. De manera que lo que, en aquellos momentos se llamó el "compromiso con el arte", fuera ligado a una ética que alcanzaba a todo su comportamiento vital y a la generalidad de su trato con el mundo.

En este sentido, Chillida actuaba a la manera en que lo habían hecho los artistas-monjes seguidores de las creencias Chen, para los cuales la actividad plástica debía de ser sólo -y no es poco- una continuidad de su actividad mental y de su comportamiento en la vida. Un comportamiento, por otra parte, en el que la ética personal se adhería a la economía del ascetismo. Asceta y medi-

\footnotetext{
${ }^{17}$ Mascaró Pons, J., «El enigma de sí mismo: la búsqueda del nos/otros» en Picazo, G. (dir.), El instante eterno, Castellón, Espai d'Art Contemporani, 2001
} 
tador, son dos formas de comportamiento ante el arte y la vida que se adecuan a la figura del escultor Chillida. ${ }^{18}$

Para concluir, una anécdota que ilustra, como ninguna otra, esa idea sobre el común espíritu de las cosas y de los seres, y en la posibilidad de una conexión entre materiales y artista. La escribió Octavio Paz en el texto que en 1979, le dedicó al artista con el título Chillida entre el hierro y la luz: "En un camino de Navarra, en el otoño de 1958, Chillida vio, medio escondida entre la hierba, una viga de madera abandonada. Al punto se detuvo y la reconoció. Mejor dicho, la oyó, pues según le refirió más tarde a Claude Esteban, le pareció oírla decir: Soy yo" $"$.

Ese soy yo cerraba el círculo de identificaciones entre sujeto y objeto, y viceversa, porque -acabemos con una pregunta en este Homenaje a Chillida puesto que él las prefería a las respuestas- ¿Chillida se reconocía a sí mismo en aquel trozo de madera o era la madera la que le reconocía a él, el que ya había escuchado su latencia mientras estaba ideando su próxima obra?

\footnotetext{
${ }^{18}$ Por José Ángel Valente sabemos que fue Braque quien le había hablado por primera vez del budismo Chen. Valente, J. A., «Sobre el lugar del dios», Diario 16, nº 489, (20/5/1995), Madrid, p. 3

${ }^{19}$ Paz, 1979, op.cit. (nota 16), p. 43
} 